\title{
Conducting Research with People with Nonverbal Autism: An Inclusive Methodological Approach
}

\author{
Karenne J Hills \\ Griffith University \\ Jayne Clapton \\ Griffith University \\ Pat Dorsett \\ Griffith University \\ Kirsty Andersen \\ Christian Heritage College
}

Abstract
Current academic literature exposes a paucity of information about people
diagnosed with Level 3 (severe social and communication deficits requiring
substantial support) autism from their own perspective. Most research
pertaining to this population has obtained data from secondary sources such as
a parent or caregiver. This paper describes the methodological approach to a
study exploring the spirituality of people with Level 3 autism, using interview as
a strategy for sourcing data. The study was intentionally designed to work
inclusively with this population, rather than conducting research on or about
them. As such, opportunity was provided for participants to be direct
respondents in the research process. Participants were seven adults, aged
between 23 and 53, who had been diagnosed with Level 3 autism. A bricolage
approach incorporating participant's personal narratives provided an inclusive
method for working with people who do not use spoken language to
communicate. As communicating with this population necessitates the use of
some type of augmentative device, certain strategies were adopted to address
the particular practical, methodological and ethical challenges confronted during
the research process. Interviews resulted in a rich source of data, providing
unique insights into the lived experience of a severely under researched
population. This study demonstrated that with researcher flexibility, a
methodology that provides participants meaningful and inclusive involvement is
not only possible, but beneficial in learning more about this marginalised group.
Furthermore, this paper introduces a methodological approach that provides a
platform for further research concerning people who do not communicate by
speech.
Key words: Nonverbal Autism; Inclusive Research; Alternative and
Augmentative Communication (AAC); Facilitated Communication
and

Corresponding author: Karenne J Hills (Karenne.hills@griffithuni.edu.au) 


\section{Introduction}

Whilst there is a growing body of research pertaining to people with autism, a paucity of research concerning those with Level 3 (severe -nonverbal)(American Psychiatric Association [APA], 2013) autism is evident (Hills, Clapton, \& Dorset, 2016). Communication and social barriers have prevented the inclusion of people with nonverbal autism as direct respondents in research opportunities to date (Siegel, 2018). This paper describes the methodological approach of a research study, Spirituality in the context of people with nonverbal autism. The principal aim was to explore the spirituality of people with autism who do not use speech to communicate, from their own perspectives. For the purposes of this paper, people diagnosed with severe (Level 3) autism (APA, 2013), are referred to as 'nonverbal' or as having 'nonverbal autism', as they do not use speech to communicate. A further aim of the study was to expand understanding concerning the use of interview as an effective tool for conducting research with people with autism who type to communicate. Specifically, this research sought to generate data from people with nonverbal autism themselves, rather than from a secondary source such as a service provider or family member, as appears common practice (e.g., Mietola, Miettinen, $\&$ Vehmas, 2017). Working with people who do not communicate with speech required careful ethical and methodological considerations. This paper will discuss the strategies used to address these factors.

\section{What is Known about Research with People with Nonverbal Autism}

There has been a significant rise in autism diagnoses in recent years (Blumberg et al., 2013; Charron, 2017). Classic diagnostic criteria for people with Autism Spectrum Disorder note language and social-communication skills ranging from minor difficulties initiating, reciprocating to and maintaining everyday social interactions, to severe difficulties in verbal and nonverbal communication (APA, 2013; Travers, Tincani, Thompson, \& Simpson, 2016). People with nonverbal autism typically present with limited social engagement, high distractibility, poor physical dexterity, little or no speech and an often-assumed cognitive disability (APA, 2013; Biklen 2005). As such, conducting research with them presents complex challenges, which has resulted in a dearth of information about this group. Therefore, although classifications of severe autism represent approximately $30 \%$ of overall diagnoses, from a scientific point of view, "we know virtually nothing about them" (Helen Tager-Flusberg communication cited in Schmidt, 2013, p. 179), particularly from their own perspective (Hills et al., 2016; Mietola et al., 2017). This is despite the increasing push within various disciplines for researchers to recognise the value of data obtained directly from the population under study rather than secondary sources such as observation, especially in regards to research with people with disability (Kirby, Dickie, \& Baranek, 2015; Morris, 2003). For instance, Ashby (2011) identified that most research concerning people with disabilities emphasises the voice of the professional, rather than the voice of the person. Whilst data gathering techniques such as observation and carer experiences are important, personal information is especially valuable for two reasons. It not only provides a more accurate picture of the complex world of the person under study, it also offers a sense of collaboration between researcher and participant (Wickenden, 2011).

The assumption that people with nonverbal autism are intellectually impaired (Biklen, 2005) has been challenged by recent research that suggests traditional methods of intelligence testing (e.g., IQ, WISC-IV) may underestimate the abilities of children with autism (e.g., Courchesne, Simard-Meilleur, \& Soulières, 2012; Grandin, 2011; Nader, Courchesne, Dawson, \& Soulieres, 2016). Indeed, such was the case with the participants of this study, none of whom had been diagnosed with a learning or intellectual impairment. 
There are particular concerns that must be addressed when designing and conducting research with vulnerable people (McDonald, Conroy, \& Olick, 2017; Thomson, Roberts, \& Bittles, 2014). For this study, the capacity of potential participants to express understanding, freely give consent, and coherently communicate if or when they wish to withdraw their participation were key ethical concerns (Hamilton et al., 2017; McDonald et al., 2017). Physical capability also needed to be gauged, including the ability to perform required tasks such as appropriately responding to interview questions via a communication device. Further, the presence of a communication facilitator in the interview room required careful consideration regarding confidentiality. These core considerations informed the development of an effective methodology designed to support the autonomy of participants.

\section{Communication considerations}

The use of Alternative and Augmentative Communication (AAC) is common amongst people with nonverbal autism. All participants of this study communicated by typing. Each identified Facilitated Communication (FC) as their preferred communication method and had been proficient with this technique for several years prior to their involvement in the research. The use of FC amongst people with communication impairments is growing worldwide (Cardinal \& Falvey, 2014), despite concerns amongst some scholars regarding the authenticity and reliability of communications (Nind, 2008). Whilst the debate continues as to the appropriate use of FC, practice based evidence has reported remarkable improvements in the ability of users to access communication strategies otherwise unavailable to them (Ashby \& CaustonTheoharis, 2012; Goddard \& Goddard, 2012).

One of the benefits of technological advances in communication aids for many people diagnosed with Level 3 autism is that previously unrecognised and highly sophisticated levels of intelligence and awareness are now observed in this population (Ashby, 2011; Ashby, Jung, Woodfield, Vroman, \& Orsati, 2015; Goddard \& Goddard; Hills et al., 2016). This discovery has transformed the ways that researchers can approach working with people with nonverbal autism.

\section{New Approaches to Research with People with Nonverbal Autism}

This study intentionally provided space and opportunity for the perspectives of people with nonverbal autism to be heard (Ashby, 2011; Biklen, 2005). By conducting research with people living the experience of nonverbal autism, rather than doing research on them (Ashby, 2011; Wickenden, 2011), the study aligned with the United Nation's (2006) Convention on the Rights of Persons with Disabilities. A recent scoping literature review confirmed the gap in available primary knowledge about people with Level 3 autism and concluded that there is a need for empirical investigation of the personal perspectives of this population, particularly in relation to spirituality (Hills et al., 2016). This conclusion provided the impetus for the current study. Therefore, the research team sought to accommodate the highlighted need for greater transparency and inclusiveness in research with individuals with nonverbal autism by validating the "frequently overlooked, under-valued and ignored" (Ridout, 2017, p. 53), voices of this group.

\section{Interview as a Data Collection Method with People with Nonverbal Autism}

Interviewing people with communication impairments is a relatively recent innovation, with scope for refinement (Siegel, 2018). The few researchers who have interviewed people with 
autism, have mainly focused on individuals who have expressive language and the ability to communicate independently (Kirby et al., 2015; Vine Foggo \& Webster, 2017). One of the only collaborative studies with people diagnosed with Level 3 autism was conducted by Douglas Biklen in 2005, who adopted an inductive approach that included the personal narratives of participants. His study provided a rare insight into the lived experience of this group. Since then, little progress has been made towards including people with nonverbal autism as direct respondents in research studies. As such, little information exists to support the necessary considerations required for conducting these studies (Teachman \& Gibson, 2018). Typical attitudes concerning the authenticity and reliability of data collected from people who require an augmentative device for communication have contributed to concerns about how to interpret data from such participants, and whether these data are in fact valid (Teachman, McDonough, Macarthur, \& Gibson, 2018). In recent years, a small number of studies have attempted to research nonverbal people using carefully chosen methodologies to address these concerns (e.g., Biklen, 1993; Philpin, Jordan, \& Warring, 2005; Soto \& Hartmann, 2006; Wickenden, 2011). As an example, Teachman and colleagues (2018) utilised a critical dialogical methodology which attempted to ensure authenticity by combining interviews with photo and visual methods of communication (see also Teachman, 2016). Nonetheless, whilst there is little research which includes people with severe autism as direct respondents, there are virtually no studies pertaining to their perspectives regarding spirituality (Hills et al., 2016).

\section{Method \\ Navigating Uncharted Territory}

Designing methods of data collection from a group of people who do not use speech to communicate, by a researcher who is not part of this demographic required a creative approach. Drawing on the scant information available from researchers such as Biklen (1993, 2005) and Ashby (2011), it became clear that this study required an inductive approach, with space for observation, abstract thinking, refinement of ideas and concepts, interpretation and flexibility (Neuman, 2011). Furthermore, the desire to include the personal stories of participants necessitated a flexible methodology which could encompass these narratives, yet also contain unexpected variables that may arise throughout the research process. In such qualitative studies, the researcher can be viewed as a bricoleur - similar to a maker of patchwork quilts - one who assembles the work by accommodating the available components (Denzin \& Lincoln, 2018). The finished patchwork reflects the quiltmaker's narrative, which becomes part of the creative process (Clapton, 2008). Whilst "capturing and expressing" stories of the bricoleur, this approach also upholds "the integrity of the participants stories" (Clapton, 2008, p. 31), thus creating new ways of understanding. As such, a bricolage methodology provided opportunity for the researcher to build trusting relationships with participants and to gauge their capacity to consent prior to the interview process.

The use of a bricolage methodology provided opportunity for creativity and flexibility by the researcher to overcome communication and social barriers commonly experienced by people with autism, as they arose. In the initial stages of the research process, a collection of grey literature provided the only information about the research topic. These works were included in the Scoping Literature Review and titled the 'Nonverbal Narrative' literature to honour the people they represented (Hills et al., 2016). The inclusion of this literature laid a foundational insight into the lived experience of people with autism who do not speak to communicate. Following this, the interweaving of interpretive and narrative perspectives into the methodological structure facilitated a further dimension, with the researcher being personally involved in the entire process. Therefore, utilising these narratives within the Bricolage methodology enabled the researcher to hold the insights gleaned from the nonverbal narrative literature, whilst coming alongside participants as they told their stories in a mutually interactive dialogue. These stories, which had never previously been told became raw data for the study 
(Butina, 2015), and were validated by the nonverbal narrative literature. The end result became an "emergent construction" (Weinstein \& Weinstein, 1991, p.161), involving an assemblage of insights which transformed and changed as different techniques or adaptations, such as social and language differences, were called upon (Denzin \& Lincoln, 2018; Kincheloe, 2001). Thus, an approach that encompasses participant's narratives encourages researchers to work relationally with them as lived stories are shared (Clandinin, 2016). For this study, the relationship between the researcher and the participants proved a vital ingredient in the process of eliciting and engaging with the stories that became a rich and valuable source of data and was facilitated by a bricolage methodology.

\section{Ethical Considerations}

The research was approved by the full committee of the relevant Institutional Human Research Ethics Committee. As would be expected when conducting research with participants with nonverbal autism, several potential ethical issues were identified during the process of designing the study. These included the intellectual capacity of the participants to understand the research process, provide informed consent, the possibility of facilitator influence and freedom to withdraw from the research. The debate concerning the authenticity of information sourced from people who use FC became a relevant ethical consideration pertaining to these issues. As such, respect for the participants' preferred method of communication was vital to the success of the study.

Furthermore, the communication and social idiosyncrasies typical of people with autism required commitment to a lengthy trust building process between the researcher and potential participants prior to the commencement of the study. This process provided opportunity for the researcher to gauge the intellectual capacity of participants while building a mutually interactive communication process with each one. Discussion concerning consent and involvement in the research with participants and their communication facilitators provided opportunity for the researcher to familiarise herself with the communication technique of each potential participant. Additionally, the content and language style of each participant provided strong evidence for the intellectual, emotional and social capacity for participation in the interview process. Trust was established with participants in a way that met the needs of each individual, thus requiring different techniques and time allocation amongst participants. This is exemplified by Participant 1 , who via his communication facilitator, engaged in a lengthy email exchange with the researcher prior to the interview, questioning her closely about the research and expressing concerns about his ability to answer questions appropriately. This participant's concern was about spiritual awareness, rather than intellectual capacity. Although this participant appeared tentative in the first interview, he approached the researcher and research assistant and shook hands with them at the end of the second interview, expressing gratitude, thus demonstrating an increased level of trust over time. In contrast to this, Participant 3, who expounded his ability to sense the energies of other people, animals and the environment several times during interviews, confirmed a level of trust with the researcher by caressing her hand to sense her "energy". Participant 2 relied on the positive reference given by her communication facilitator and friend, while trust was established for Participant 4 by the nature of the research, a topic of specific interest to him. These individual needs each required a degree of interpretation, negotiation and flexibility by the researcher.

As such, participants were as well prepared as possible for their interviews, with many expressing eagerness for the opportunity to contribute to the research. This approach was also identified as necessary for successful research with people with autism by Haas and associates (2016), who observed 
... adults on the autism spectrum will be deterred from engaging in research if autism researchers do not clearly demonstrate in the research design and the conduct of their studies, from recruitment through to data collection and reporting in a way that they both understand and that is sensitive to particular and individual cognitive and communication styles, behaviours and sensory needs of people on the autism spectrum. Insensitivity to the particular needs of adults on the autism spectrum [...] manifested as an inhibitor to participation. (p. 1799)

It should be noted that all participants of this study had the ability to read at an age appropriate level.

\section{Participants}

Participants were seven adults who had been diagnostically placed on the severe end of the autism spectrum, and therefore do not communicate by use of oral speech. All lived in a large metropolitan city either in Australia or the USA. Prior to learning to use a communication device they all relied on body language (e.g., gestures or behaviours) to communicate (Table 1). 
Table 1: Participant Demographics
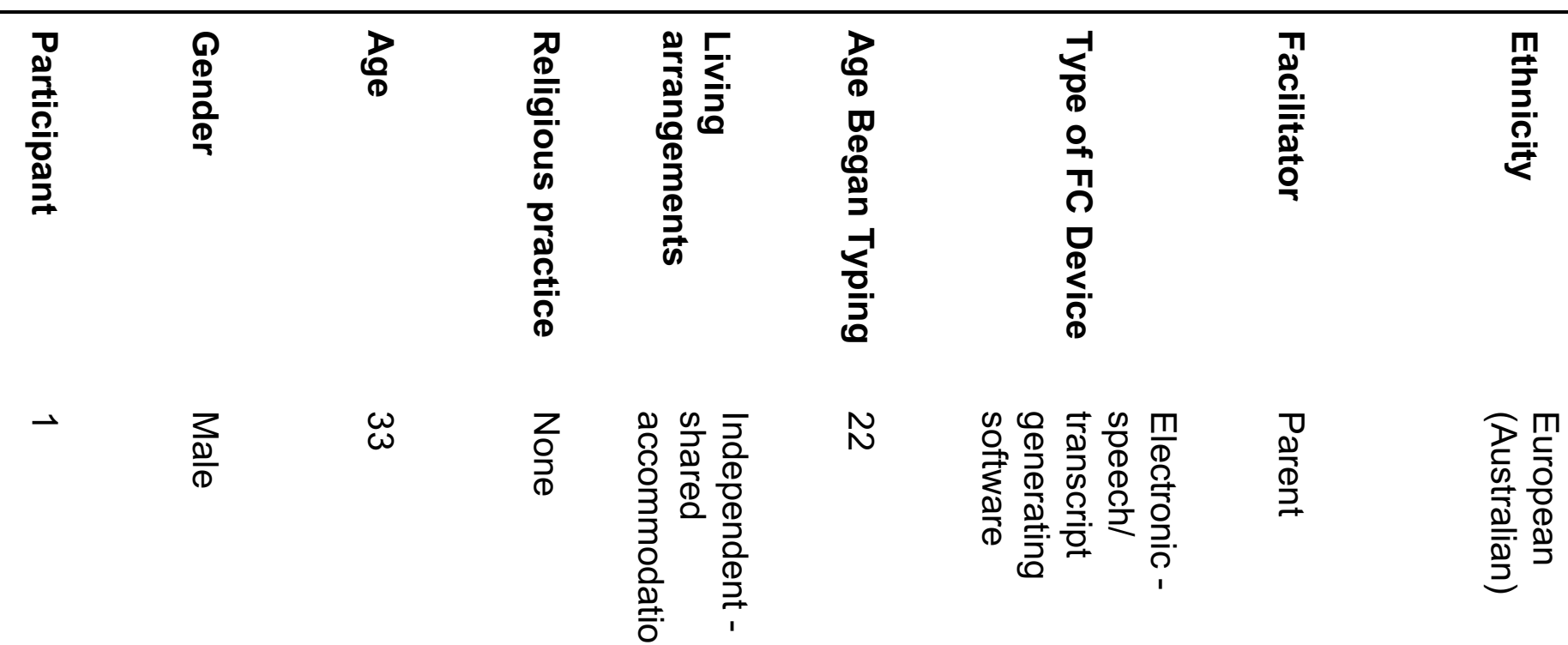

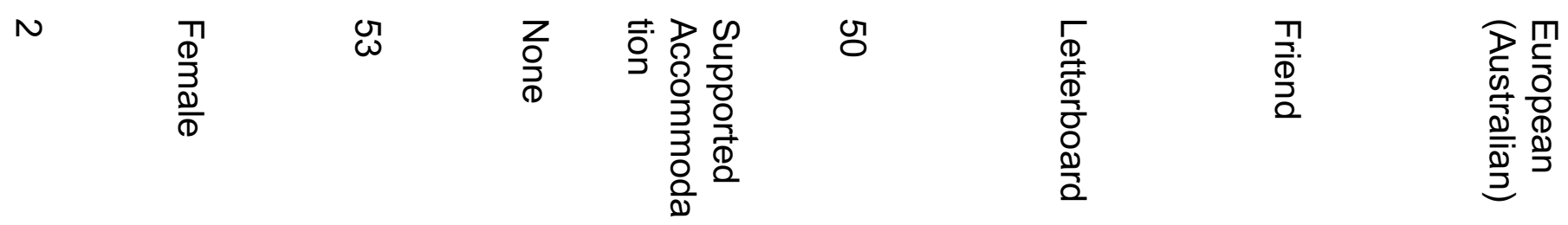

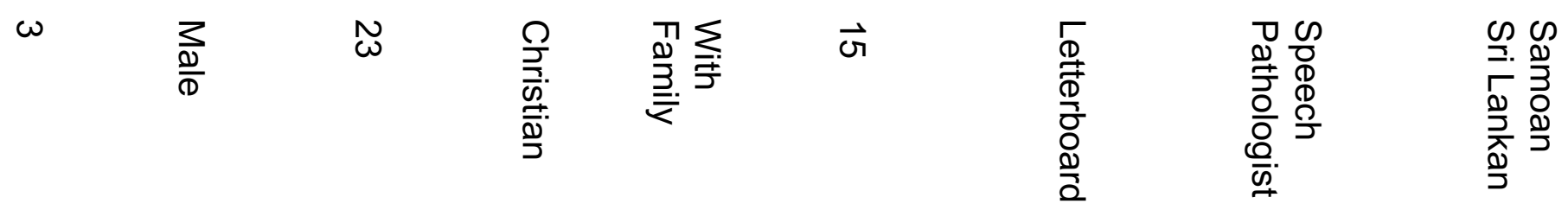
$\therefore \quad \frac{3}{\bar{D}}$

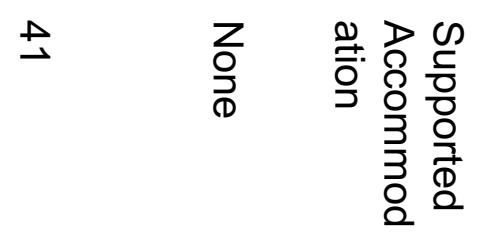
$\vec{\omega}$
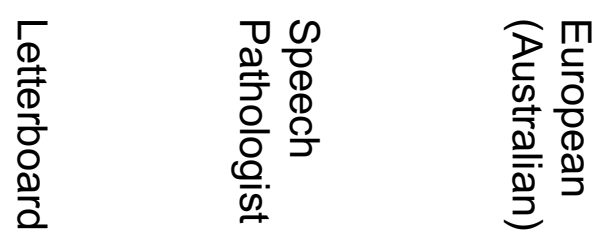

or

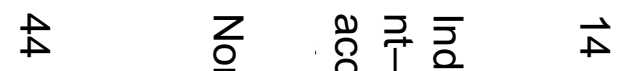

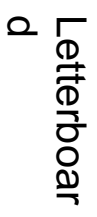

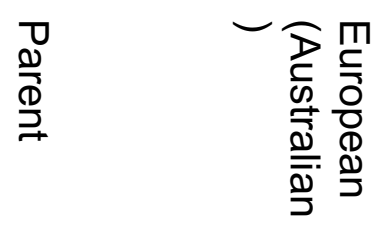

$の$
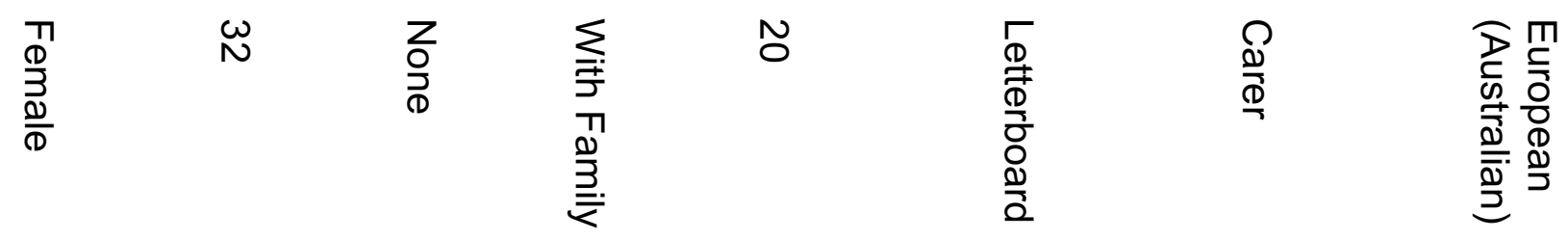
At the time of this research, each participant was skilled in the use of $\mathrm{FC}$, having used their devices for several years prior to the commencement of the study. Before being introduced to FC, communication was restricted to methods such as gesture or pictorial process, which many described as confining 'conversation' to expressing simple choices or needs and limiting their ability to share personal information (Blackman, 1999; Bonker \& Breen, 2011; Goddard \& Goddard, 2012). The Facilitated Communication process required some degree of support from a facilitator who was well known to the particular participant. This support varied from individual to individual. One participant required no more than a light touch to the corresponding shoulder of the typing finger, another by a similar light touch to the elbow. A further participant required support to the typing hand, forming his own pointing finger, however if an inadvertent letter was touched, this participant backspaced independently with his nondominant hand. Other participants required support for their pointing hand similar to the illustrations below (Figures 1 and 2).

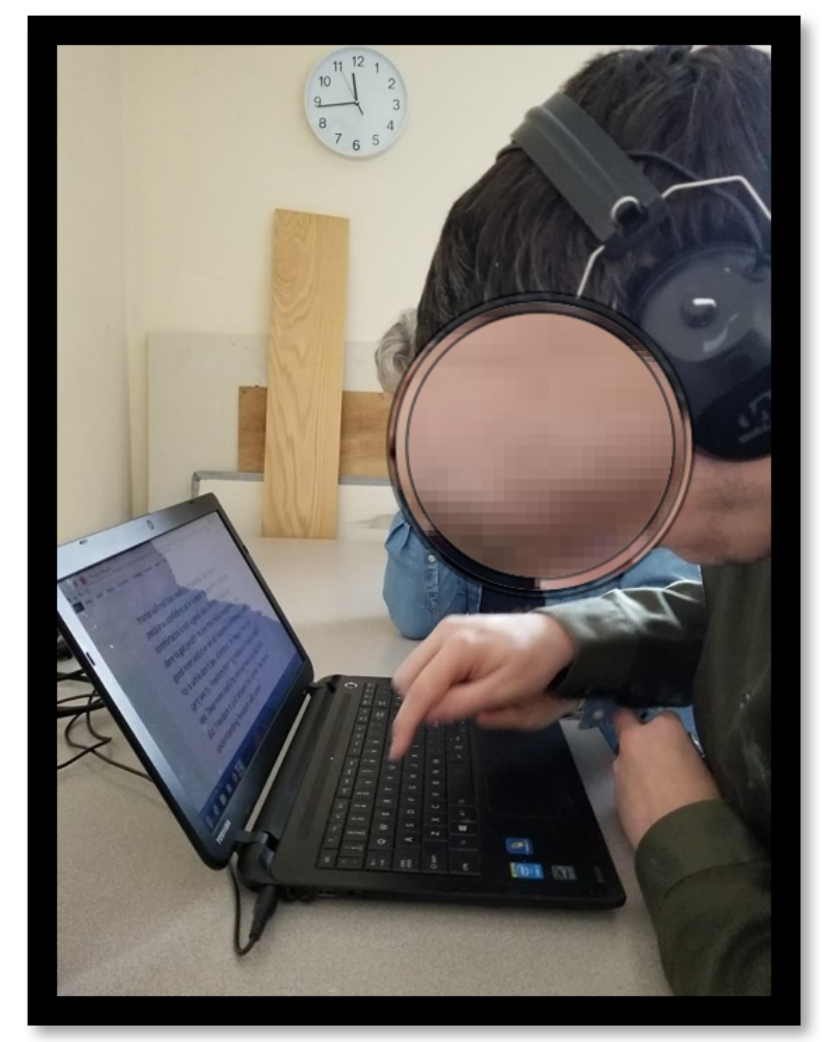

Figure 1. Facilitator Supported Communication, faces pixelated for de-identification (Credit: Nick Bursh) 


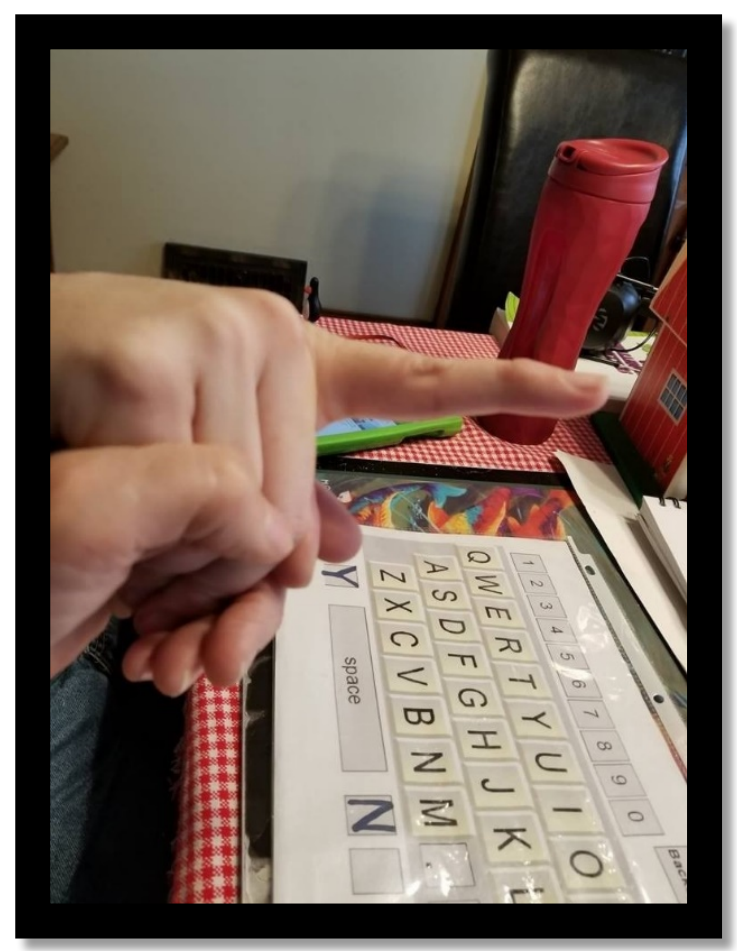

Figure 2. Support for Pointing Hand (Credit: Nick Bursh)

\section{Recruitment}

Sampling methodology for this study was opportunistic, as there were limited opportunities for recruitment. The American participant was recruited from a personal encounter with the researcher at an international conference. The remaining six were recruited from an Australian poetry group exclusively for people who do not speak. The group of approximately 20 members was independently approached by the researcher prior to the commencement of the study via the poetry group facilitator (who speaks to communicate). They were then provided with written information concerning the study and invited to participate. Thus, the group facilitator had an important role in explaining the research to the participants and acted as a link by coordinating communication between the research team and potential participants (Nind, 2008). The parents of the American participant were present for the initial conversation explaining details of the study, so they provided a similar support role. As per typical research conventions, after a full understanding of the process was communicated a consent form was signed by the participant in the presence of the facilitator, research assistant and the researcher. In the interest of best practice, the participants were also informed that they had a level of control over the interview; the choice of what information to share, which questions to answer, and the option of terminating the interview at any time. Further, as a condition of ethics approval, it was made clear that counselling was available to participants by a qualified psychotherapist should it be required, however no participant requested this.

\section{Data Collection}

The vulnerability of the participants remained forefront of the researcher's awareness throughout the interview process. The study was structured with the intention to empower participants by considering their autonomy and including them as much as possible in the research process, rather than viewing them as research 'subjects' under study. For Australian participants, data were collected through face-to-face one-on-one interviews which lasted approximately one hour. Each of these six participants requested a second, follow-up interview. Interview questions were developed by the research team and were informed by the findings of the Scoping Literature Review (see Appendix 1). The questions were designed 
to explore the spiritual understandings and experiences of participants from their own perspectives. In order to maintain focus, the researcher did not adopt a duel role of interviewer and communication facilitator. A trained facilitator well known to the participant supported them as they responded to questions. One participant chose to type on an iPad whilst the other five communicated by pointing to letters on a portable letter board. The American participant provided typed responses to the first round of interview questions with the support of his communication facilitator, which were then emailed to the researcher. Responses from this participant were authenticated via a SKYPE interview with he and his facilitator.

Present at each interview were the researcher, a research assistant, the participant and their chosen facilitator. Each participant and their facilitator independently signed consent (participants) or confidentiality forms (facilitators) in full view of the researcher prior to the commencement of the interview process, after it had been explained that in addition to the research team their facilitator would know their responses. Interviews were conducted in a conversational manner, with questions asked verbally by the researcher and the participant typing their response on their communication device. Facilitators read aloud responses as the participant typed them, and the researcher was also able to watch the letterboard as the participant typed. The researcher also asked participants periodically throughout each interview whether they wished to add to or clarify their responses or cease the interview. This was particularly the case if a participant paused for a long time during the interview. The research assistant manually transcribed all interviews verbatim in situ. After finalising the first round of interviews, data were consolidated, initial themes identified and from this information a second round of similarly structured interviews were then conducted.

\section{Results}

\section{Iteration}

Post interview, each participant was given copies of his/her transcripts as recorded by the research assistant, to provide opportunity for modification before data were analysed. Only one participant requested slight word changes to one interview transcript. Two participants also made use of a device that provided a printed transcript of their responses during the interview. These transcripts were matched to the transcript notated by the research assistant. Participants were also provided opportunity to contact the researcher by email at any time to ask questions or raise concerns, although it was acknowledged that the individuals were reliant on their facilitator to assist them to write/respond to emails. Even so, one participant contacted the researcher (via the facilitator) post-interview, to add further information concerning a response to an interview question.

During their interviews, two participants explained that using devices takes significant time and energy and that their access to facilitators (and thus to communicate meaningfully) was limited. In their view, this means that what they do communicate is well thought out and words are carefully chosen for economy and ease. Indeed, the research revealed that information shared was detailed, very direct and unhampered by the asides and irrelevancies often found in verbal speech.

We don't waste time with rubbish. We get to the point. (Participant 1, Interview 1)

\section{Engagement}

Social communication challenges typical to the autistic experience, could result in an incorrect assumption that people with nonverbal autism would be difficult to engage. It transpired however, that whilst participants were highly animated, often getting up during the interview to 
walk around the room, fiddling with personal items such as pieces of cord or fidget sticks and rarely making eye contact, they were engaged in the process from the beginning of the interview. Furthermore, participants demonstrated understanding of the interview process as it transpired. The information provided was always relevant to the question and presented in full sentences typical of conversational speech, rather than 'yes'/'no' responses.

All appeared aware of their own 'limits' and requested (and were provided with) short tea breaks, and freedom of movement. For example, Participant 2 preferred to walk continuously into and out of her house which required the research team to conduct part of the interview standing, and to follow the participant between locations. It emerged that one hour seemed to be the limit that each participant was able to maintain concentration. Even so, each was able to express unprompted, via their communication device, when they were ready to terminate the session. Remarkably, six of the seven participants requested that the session end after an hour due to fatigue, but that the research team return for a second interview.

I have had enough today. Come back next Thursday to hear more from my story. (Participant 2, Interview 1)

The fatiguing nature associated with the use of alternate forms of communication was also identified by Teachman and Gibson (2018) who attempted to minimise the issue by conducting interviews in participants' own homes and with their usual "communication partner" (p. 5), rationalising that familiarity would reduce their fatigue. It is unclear whether these particular factors do impact fatigue however in this study participants were given their choice of location and facilitator and provided with a copy of the interview questions in advance to allow them time to formulate their responses.

It was also noted by the research team that participants' behaviour was often incongruent with the content of their written communication. For example, facial expressions would sometimes imply an emotion such as anger, whereas the content of their communication indicated something very different. This observation is supported by research conducted by Brewer and associates (2016) who found that neurotypical people have difficulty in accurately identifying the emotional expressions of people with autism. Additionally, the seeming reluctance of people on the autism spectrum to engage in socially expected ways such as with eye contact has been noted by several researchers, however this idiosyncrasy does not necessarily indicate that they are detached (Milne, Scope, Griffiths, Codina, \& Buckley, 2013; Trevisan, Roberts, Lin, \& Birmingham, 2017).

Several participants reported giving deep consideration to their responses before meeting with the researcher. This demonstrated both interest in participating and an ability to focus, even though their behaviour during the interview process could have been interpreted very differently. Indeed, all displayed a high degree of enthusiasm, jumping straight into conversation directly after being greeted.

So ladies [addressing the researcher and research assistant] what's the deal? I'm very happy to see you [...] Thanks for asking me to be part of this research. (Participant 4, Interview 1)

The heightened sensitivity of this population further contributed to behaviours that may have indicated a lack of engagement, however, in actual fact participants were very able to maintain focus on the discussion whilst attending to their social needs. For example, Participant 3 
needed to fiddle with some cords while he spoke, and the more excited he became about the content of his answers, the more he appeared to focus on the cords. However, he was quick to pick up the thread of his discussion once he had recalibrated himself, and unprompted, expressed awareness and frustration about his behaviours, explaining that they are uncontrollable and did not indicate distress or disengagement.

I'm gibbery and flibbery and it's hard to control myself. (Participant 3, Interview 1)

The researcher was careful not to interpret such behaviours, relying on the typed communication along with the facilitator's personal knowledge of the participant to monitor changes in mood. This issue was highlighted when Participant 4 mentioned an image of a "black dog", commonly associated with depression (McCrae, 2016). Interestingly, through careful questioning the participant indicated that the association was actually positive, and he was eager to elaborate on the significant impact of this metaphoric dog on his life.

As such, careful attention from the researcher was required to work with these types of idiosyncrasies, rather than interpreting them as congruent with similar behaviours should they be noted amongst neurotypical people. The ethical responsibilities of the researcher to identify and monitor any distress, meant that careful attention was given to these nuances during the research process. When incongruencies did occur between a participant's words and behaviours, the researcher was intentional about enquiring as to their correct meaning. These adaptions demonstrate the importance of researcher education and understanding pertaining to specific research populations.

\section{Authenticity}

Given the debate concerning $\mathrm{FC}$, issues of authenticity and reliability required careful consideration to ensure diligence both in the design and implementation phases of the study. Acknowledging this, the research team carefully considered possible strategies to ensure rigour. Firstly, participant responses were read aloud by the research assistant after each interview question to confirm accuracy in transcription. The fact that participants often moved around the room or made noises meant that occasionally they had to correct a word on their transcript. Secondly, the participants did not use the same facilitator. Seven interviewees used six different facilitators, in six different locations. However, strong consistent themes emerged from the collective data, along with similar stories, attitudes and life experiences, demonstrating that data were not manufactured by a facilitator. Furthermore, in data collected from the two participants who used the same facilitator, linguistically each participant's choice of words was markedly different from that of their facilitator, and the experiences of the participant were personally unique to each one. For example, one participant was prone to the use of quite 'colourful' and expressive language, as opposed to the facilitator, who was more moderate in her language choices. The other carried out the interview in the presence of his mother, who validated parts of the story unknown to the facilitator. This participant was also chided by his mother for using a particular word she did not approve of, providing further evidence of the authenticity of the participant's words.

In all cases the facilitator appeared to be genuinely surprised at some of the content of the participant's responses. For example, at the end of an interview one facilitator asked the participant "Have you ever talked about this before?" To which the participant replied:

No. You never asked. (Participant 2, Interview 2) 
This could be partially attributed to the practical nature of their usual daily communication which tended to focus more on basic needs rather than a conversational exchange. This is consistent with the findings of Remington-Gurney (2017), who identified the basic human right of conversation as distinct from communication. Additionally, whilst most participants used letterboards to communicate, one preferred to use an iPad with speech and transcript generating software. These differences between participants coupled with strong common themes provided evidence of the authenticity of content.

\section{Facilitator Influence}

Whilst the facilitators provided no content in the responses of participants to interview questions, it was found that their presence influenced the interview process in unanticipated ways.

The disjointed responses of participants meant that some facilitators filled pauses in the interview with personal asides, creating the necessity for the researcher to purposefully address the next question to the participant by name in order to progress the interview. Facilitators proved to be a valuable source of background information concerning the participant, however as it was the intent of the research to gain the perspectives of people with nonverbal autism, questions were directed to the participant. Possibly in response to the facilitator interruptions two participants seemed frustrated with their facilitators, stabbing the letterboard in apparent annoyance, turning away and refusing to engage. One requested that the interview resume.

That is good. Let's stick to topic. (Participant 5, Interview 2)

These interruptions contributed to the broken communication of the participant and impacted the speed of the interviews. It should be noted that only the responses of participants were analysed. In future studies it may be beneficial to restrict facilitator/researcher chat to prior or post interview and tea breaks.

\section{Conversational Challenges}

Participants' method of communication and the effort required to point individually at letters on a letterboard/type, often resulted in disjointed responses as some participants communicated in incomplete sentences at times. This process, coupled with the propensity to distractibility of the participants, meant the researcher was often left waiting for the last few words of the sentence. This required both patience and focus on the part of the researcher who therefore needed to remember what the last question was, along with the participant's response over a number of phrases and pauses. This occasionally required the piecing together of individual words into coherent sentences. One of the roles of the communication facilitator is to provide emotional support such as prompting, as in the example below.

P6: It makes me [pause] think that not everything is [pause]

Facilitator: Keep going.

P6: so yucky [pause]

Facilitator: Try and keep going.

P6: and [pause]

Facilitator: Come on, try to keep going.

P6: that not everybody is mean. (Participant 6, Interview 1) 
In situ, manual transcription of the interviews greatly assisted with this challenge and is recommended for future research, as the response of the participant as transcribed could immediately be read aloud as a reminder of what had been communicated. Participants also communicated with significantly variable speeds, something which had not been anticipated given the assumption that communication with the use of communication devices was likely to result in a very slow conversation. It could be assumed that participants with communication challenges may benefit from modified or simplified interview questions, and it is acknowledged by the authors that this type of support could be useful in particular contexts. In this study however, participants were very experienced with their communication devices and did not require this accommodation. While some participants communicated slowly and in broken sentences thus requiring some repeating of questions, others typed at what could be considered speed comparable to conversational speech. This highlights the need to put aside assumptions when performing research with little-researched groups, and to maintain a flexible and open approach.

\section{Discussion and Implications}

This study has demonstrated that inclusively involving participants with nonverbal autism in the research process is not only possible but necessary to the understanding of their lived reality. Interviews provided an unexpectedly rich source of data (see Hills, Clapton, Dorsett, and Andersen, 2019 for full discussion of study results). The value of seeking information directly from participants is evident, not solely in terms of the quality of data, but also as participants repeatedly expressed gratitude and excitement at the opportunity to communicate their story in their own way. Each one relayed that they were deeply moved by the experience of communicating to someone about parts of their lived experience that they had never expressed before.

I'm so enjoying this time of being a part of something amazing. (Participant 4, Interview 2)

In support of Biklen's (2005) approach, interviews proved a successful method of collecting data from people with nonverbal autism, with a relatively small number of accommodations necessary to address challenges. It must be acknowledged however, that success seems to hinge on the capacity of the researcher for flexibility. This is especially the case when preconceived ideas about the likely behaviours and needs of a particular group drives the choice of data collection methods and interview style.

This study demonstrates that barriers to conducting research with people who are nonverbal can be addressed through greater consideration of strategies which allow for communication by means other than speech. Environmental and behavioural elements are an important consideration with the need for regular breaks, familiarity and freedom of movement necessary additions to the methodological design. Whilst difficult to eliminate, the impact of the facilitator on the interview can be minimised by providing participants with interview questions in advance so they may need less thinking time. However, it is acknowledged that the nature of the communication alone will impact the speed of the interview and amount of data generated. In short, participants will feel more included and autonomous if questions are directed to them rather than the facilitator and accommodations to their particular physical and sensory needs are integrated into the interview approach. With the growing number of children being diagnosed with severe autism, along with the number of adults who remain voiceless as they wait for a suitable communication strategy to be available to them, further research with this population is imperative from a number of perspectives. Not only is there enormous scope for understanding the lived experience of people with nonverbal autism, further research 
concerning appropriate methods of assisted communication is vital to achieving this objective. Interestingly, all participants of this study used letterboards or electronic devices as their preferred method of communication, which impacted the amount of data able to be sourced at each interview. The need for future research with nonspeaking participants who use other communication methods such as text to speech programs is highlighted and strongly recommended, as these methods will provide helpful accommodations to data sourcing processes.

This methodological approach demonstrates that first-hand research with people who type to communicate is indeed possible and should be considered as a viable consideration for future research with people with nonverbal autism. Furthermore, it has helped to provide agency, value and a platform for expression to a previously voiceless population. Now that an inclusive methodological perspective to conducting research with people with severe autism has been tested, future opportunities to expand the body of knowledge concerning this group abound.

\section{References}

American Psychiatric Association. (APA, 2013). Diagnostic and statistical manual of mental disorders. Fifth edition (DSM-5). Washington, DC: Author.

Ashby, C. (2011). Whose "voice" is it anyway?: Giving voice and qualitative research involving individuals that type to communicate. Disability Studies Quarterly, 31, 121. Retrieved from http://dsqsds.org/article/view/1723/1771

Ashby, C., \& Causton-Theoharis, J. (2012). "Moving quietly through the door of opportunity": Perspectives of college students who type to communicate. Equity \& Excellence in Education, 45, 261-282. doi: 10.1080/10665684.2012.666939

Ashby, C., Jung, E., Woodfield, C., Vroman, K., \& Orsati, F. (2015). 'Wishing to go it alone': The complicated interplay of independence, interdependence and agency. Disability \& Society, 30, 1474-1489. doi: 10.1080/09687599.2015.1108901

Biklen, D. (1993). Communication unbound: How facilitated communication is challenging traditional views of autism and ability/disability. New York, NY: Teachers College Press.

Biklen, D. (2005). Autism and the myth of the person alone. New York, NY: New York Press.

Blackman, L. (1999). Lucy's story. Autism and other adventures. Brisbane, Australia: Book in Hand.

Blumberg, S., Bramlett, M., Kogan, M., Schieve, L. A., Jones, J. R., \& Lu, M. C.

(2013). Changes in prevalence of parent-reported autism spectrum disorder in school-aged US children: 2007 to 2011-2012 (National Health Statistics Reports No. 65). Hyattsville, MD: National Center for Health Statistics.

Bonker, E., \& Breen, V. (2011). I am in here: The journey of a child with autism who cannot speak but finds her voice. Grand Rapids, MI: Revell.

Brewer, R., Biotti, F., Catmur, C., Press, C., Happe, F., Cook, R., \& Bird, G. (2016).

Can neurotypical individuals read autistic facial expressions? Atypical production of emotional facial expressions in Autism Spectrum Disorders. Autism Research, 9, 262-271. doi: 10.1002/aur.1508

Butina, M. (2015). A narrative approach to qualitative inquiry. Clinical Laboratory Science, 28, 190-196. doi: 10.29074/ascls.28.3.190

Cardinal, D., \& Falvey, M. (2014). The maturing of facilitated communication: A means toward independent communication. Research and Practice for Persons with Severe Disabilities, 39, 189-194. doi: 10.1177/1540796914555581

Charron, R. (2017, August 28). Autism rates across the developed world. Focus for Health.Retrieved from https://www.focusforhealth.org/autism-rates-across-the- 
developed-world/

Clandinin, D. J. (2016). Developing qualitative inquiry: Vol. 9. Engaging in narrative inquiry (J. M. Morse, Ed.). Oxon, UK: Routlege.

Courchesne, V., Simard-Meilleur, A. A., \& Soulières, I. (2012). Intelligence testing in autistic children regarded as very low-functioning: The good surprise. Paper presented at International Meeting for Autism Research, Toronto, Canada.

Denzin, N., \& Lincoln, Y. (Eds., 2018). The Sage handbook of qualitative research ( 5th ed.). Thousand Oaks, CA: Sage.

Goddard, P., \& Goddard, D. (2012) I am intelligent: From heartbreak to healing - A mother and daughter's journey through autism. Guilford, CT: Skirt!

Grandin, T. (2011). The way I see it. A personal look at Autism and Asperger's (2nd ed.). Arlington, TX: Future Horizons.

Haas, K., Costley, D., Falkmer, M., Richdale, A., Sofronoff, K., \& Falkmer, T. (2016). Factors influencing the research participation of adults with autism spectrum disorders. Journal of Developmental Disorders, 46, 1793-1805. doi: 10.1007/s10803-016-2708-6

Hamilton, J., Ingham, B., McKinnon, I., Parr, J., Yuen-Chong Tam, L., \& Le Couteur, A. (2017). Mental capacity to consent to research? Experiences of consenting adults with intellectual disabilities and/or autism to research. British Journal of Learning Disabilities, 45, 230-237. doi: 10.1111/bld.12198

Hills, K., Clapton, J., \& Dorsett, P. (2016). Towards an understanding of spirituality in the context of nonverbal autism: A scoping review. Journal of Disability \& Religion, 20, 265-290. doi: 10.1080/23312521.2016.1244501

Hills, K., Clapton, J., Dorsett, P., \& Andersen, K. (2019). Spirituality in the context of nonverbal autism: A research process - Findings and Analysis. Journal of Religion and Disability, 23, 365-386. doi: 10.1080/23312521.2019.1682104

Kincheloe, J. (2001). Describing the Bricolage: Conceptualizing a new rigor in qualitative research. Qualitative Inquiry, 7, 679-692. doi: 10.1177/107780040100700601

Kirby, A., Dickie, V., \& Baranek, G. (2015). Sensory experiences of children with autism spectrum disorder: In their own words. Autism, 19, 316-326. doi: $10.1177 / 1362361314520756$

McCrae, N. (2016). The 'black dog': Depression in old age. British Journal of Neuroscience Nursing, 12, 126-131. doi: 10.12968/bjnn.2016.12.3.126

McDonald, K., Conroy, N., \& Olick, R. (2017). What's the harm? Harms in research with adults with intellectual disability. American Journal on Intellectual and Developmental Disabilities, 122, 78-92. doi: 10.1352/1944-7558-122.1.78

Mietola, R., Miettinen, S., \& Vehmas, S. (2017). Voiceless subjects? Research ethics and persons with profound intellectual disabilities. International Journal of Social Research Methodology, 20, 263-274. doi: 10.1080/13645579.2017.1287872

Milne, E., Scope, A., Griffiths, H., Codina, C., \& Buckley, D. (2013). Brief report: Preliminary evidence of reduced sensitivity in the peripheral visual field of adolescents with autistic spectrum disorder. Journal of Autism and Developmental Disorders, 43, 1976-1982. doi: 10.1007/s10803-012-1730-6

Morris, J. (2003). Including all children: Finding out about the experiences of children with communication and/or cognitive impairments. Children \& Society, 17, 337-348. doi: $10.1002 / \mathrm{CHI} .754$

Nader, A., Courchesne, V., Dawson, M., \& Soulieres, I. (2016). Does WISC-IV underestimate the intelligence of autistic children? Journal of Autism and Developmental Disorders, 46, 1582-1589. doi: 10.1007/s10803-014-2270-z

Neuman, L. (2011). Social research methods: Qualitative and quantitative approaches. Boston, MA: Allyn \& Bacon.

Nind, M. (2008). Conducting qualitative research with people with learning, communication and other disabilities: Methodological challenges. ESRC National Centre for Research Methods Review Paper. UK: ESRC National Centre for Research Methods, University of Southampton. 
Remington-Gurney, J. (2017). Conversations without speech: A qualitative investigation of the strategies used by adult communication assistants in Queensland (Unpublished doctoral dissertation). Griffith University, Brisbane, Australia.

Ridout, S. (2017). The autistic voice and creative methodologies. Qualitative Research Journal, 17, 52-64. doi: 10.1108/QRJ-07-2016-0046

Schmidt, C. (2013). Severe autism, often slighted, now targeted for study. Science, 342, 179-179. doi: 10.1126/science.342.6155.179

Siegel, M. (2018). The severe end of the spectrum: Insights and opportunities from the Autism Inpatient Collection (AIC). Journal of Autism and Developmental Disorders, 48, 3641-3646. doi: 10.1007/s10803-018-3731-6

Soto, G., \& Hartmann, E. (2006). Analysis of narratives produced by four children who use augmentative and alternative communication. Journal of Communication Disorders, 39, 456-480. doi: 10.1016/j.jcomdis.2006.04.005

Teachman, G. (2016). Interrogating inclusion: Critical research with disabled youth who use augmentative and alternative communication (Unpublished doctoral dissertation). University of Toronto, Canada. Retrieved from https://tspace.library.utoronto.ca/bitstream/1807/73207/1/Teachman_Gail_201606_ PhD_thesis.pdf

Teachman, G., \& Gibson, B. (2018). Integrating visual methods with dialogical interviews in research with youth who use augmentative and alternative communication. International Journal of Qualitative Methods, 17, 1-12. doi: 10.1177/1609406917750945

Teachman, G., McDonough, P., Macarthur, C., \& Gibson, B. (2018). A critical dialogical methodology for conducting research with disabled youth who use augmentative and alternative communication. Qualitative Inquiry, 24, 35-44. doi: $10.1177 / 1077800417727763$

Thomson, A., Roberts, P., \& Bittles, A. (2014). Navigating the maze: Ethics approval pathways for intellectual disability research. Journal of Medical Ethics, 40, 782-786. doi: 10.1136/medethics-2012-100899

Travers, J. C., Tincani, M., Thompson, J., \& Simpson, R. (2016). Picture Exchange Communication System and Facilitated Communication: Contrasting an evidencebased practice with a discredited method. In B. G. Cook, M. Tankersley \& T. J. Landrum (Eds.), Instructional practices with and without empirical validity (Advances in learning and behavioral disabilities, Vol. 29, pp. 85-110). Bingley, UK: Emerald Group.

Trevisan, D. A., Roberts, N., Lin, C., \& Birmingham, E. (2017). How do adults and teens with self-declared Autism Spectrum Disorder experience eye contact? A qualitative analysis of first-hand accounts. PLOS ONE, 12, e0188446. Retrieved from https://journals.plos.org/

United Nations. (2006). Convention on the rights of persons with disabilities and optional protocol. New York, NY: Author. Retrieved from http://www.un.org/disabilities/documents/convention/convoptprot-e.pdf

Vine Foggo, R., \& Webster, A. (2017). Understanding the social experiences of adolescent females on the autism spectrum. Research in Autism Spectrum Disorders, 35, 74-85. doi: 10.1016/j.rasd.2016.11.006

Weinstein, D., \& Weinstein, M.A. (1991). Georg Simmel. Sociological flaneur bricoleur. Theory, Culture \& Society, 8, 151-168. doi: $0.1177 / 026327691008003011$

Wickenden, M. (2011). Talking to teenagers: Using anthropological methods to explore identity and the lifeworlds of young people who use AAC. Communication Disorders Quarterly, 32, 151-163. doi: 10.1177/1525740109348792 


\section{Appendix 1}

\section{Interview One Questions}

1. What does spirituality mean to you?

2. In what ways does spirituality impact your life?

3. In what ways does language, or the absence of verbal language, impact your spirituality?

4. In what ways do you conceptualise or think about your spirituality other than by the use of conventional language?

5. What is your concept of "God", the "Divine", or a "higher power"? Does this concept impact your spirituality? If yes, please describe.

6. Describe your experiences concerning prayer or meditation.

7. Do you recognise a difference in your spirituality now, as opposed to before you were able to express yourself by using assisted communication? If yes, in what ways?

8. Does sharing your spirituality with other people impact you in any way? If yes, please describe.

9. What would you like others to know about spirituality as a result of your experiences?

\section{Interview Two Questions}

1. One of the strong themes that I noticed was how much you seem to care about other people, animals and even nature. You seem to hold a big awareness of the planet, and deeply care about many aspects of our world. In what ways do you think that your autism contributes to this concern?

2. Another thing I noticed in terms of spiritual experiences, was that they somehow seemed to be connected to, or used to help you deal with hardships in life. What more can you tell me about this?

3. Another theme that came through was that you tend to think in pictures. Does this impact your spirituality at all? Do you ever have visions or other types of internal picture experiences?

4. Do you ever get a picture of what is going to happen ahead of time?

5. Do you think your unique genius or giftedness extends to your spirituality, or your ability to experience things of a spiritual nature? How might this be so?

6. Because of your autism, you seem to be dependent on other people for many of your life needs, especially communication. Yet, another strong theme that emerged from the first interviews was that you would like to contribute back to society somehow. Can you see an interdependent type of relationship being of value to you, and to society? How would this look do you think? 
7. You describe and demonstrate a high intelligence. Does your spirituality impact your intelligence, or vice versa?

8. Do you control how and when you might have a spiritual experience, or is it a more random thing?

9. If you were provided a platform for telling the world about your life, do you think you would have something to say about spiritual matters or God?

\section{Biographical Notes}

Dr Karenne Hills is a lecturer in the Counselling Program at Australian Institute of Professional Counsellors. Her Doctoral thesis explored the spiritual experiences of people with non-verbal autism. She has a special interest in the theological and spiritual considerations for people with disability, an interest born largely out of her personal journey with her two sons, each of whom live with significant disabilities. Karenne has presented her work at national and international conferences.

Prof Jayne Clapton, BA, Ph.D. is an Adjunct Professor in the School of Human Services and Social Work at Griffith University in Queensland, Australia. Jayne is a Disability Studies scholar who, for many years, has researched the relationship between ethics, theology, inclusion and disability, particularly intellectual disability. Jayne previously convened an international special interest research group on ethics and intellectual disability and has presented at national and international conferences.

Dr Pat Dorsett is a Senior Lecturer in the School of Human Services and Social Work. Her research is primarily in the disability and rehabilitation fields. She has a particular interest in the lived experience of people in the context of life challenges. Her research has been published in high quality peer reviewed journals and presented at national and international conferences.

Miss Kirsty Andersen has conducted research across a number of disciplines including counselling, education, religion, and suicide, and has several publications in these areas. Her research interests include disability, and spiritual phenomena in relation to mental health. 